\author{
DOMINIKA PLUST, EWELINA MARCINIAK, BARBARA CZERNIEJEWSKA- \\ SURMA, ORINA SURMA, PIOTR ZAPLETAL
}

\title{
OCENA AKTYWNOŚCI PRZECIWUTLENIAJĄCEJ MIODÓW PITNYCH DWÓJNIAK I ZMIANY TEJ AKTYWNOŚCI W WYNIKU PRZECHOWYWANIA
}

\begin{abstract}
Streszczenie
Miody pitne to wyroby alkoholowe powstające w wyniku fermentacji brzeczki miodowej. Surowce do produkcji miodów pitnych (miód, przyprawy korzenne, soki owocowe) są bogatym źródłem związków charakteryzujących się dobrymi właściwościami przeciwutleniającymi. Właściwości te oznaczano w wodnych roztworach miodów pitnych bezpośrednio po otwarciu butelek oraz po 7 i 180 dniach przechowywania. W badaniach wykazano, że miody pitne (1:1) wyróżniały się dobrymi, ale zróżnicowanymi właściwościami przeciwutleniającymi. Dwójniaki z dodatkiem soków owocowych i/lub niepoddane procesowi sycenia odznaczały się wyższą aktywnością przeciwutleniającą (TEAC) na poziomie $1,08 \div$ 2,36 mM TE/l w porównaniu z miodami syconym i/lub bez dodatków $0,51 \div 0,73 \mathrm{mM} \mathrm{TE} / 1$. Właściwości redukujące (FRAP) mieściły się w zakresie 1,28 $\div 3,07 \mathrm{mM} \mathrm{TE} / 1$. Zaobserwowano istotne obniżenie wartości tego parametru podczas przechowywania. W pracy wykazano także, że zastosowanie dodatkowych składników przez producenta może spowodować prawie trzykrotny wzrost zawartości polifenoli ogółem (miód pitny lipowy bez dodatków - 122,6 mg kwasu galusowego/l; miód z wyciągiem z kory dębu, ziół i przypraw - 348,2 mg kw. galusowego/l). Stwierdzono, że zarówno krótkotrwałe, jak i długotrwałe przechowywanie miodów pitnych w większości przypadków nie wpłynęło znacząco na ich zdolności przeciwutleniające, jednak miało istotny wpływ na zdolności redukujące oraz zawartość polifenoli ogółem.
\end{abstract}

Słowa kluczowe: miód pitny dwójniak, właściwości przeciwutleniające, TEAC, FRAP, polifenole ogółem, przechowywanie chłodnicze

Dr inż. D. Plust, mgr inż. E. Marciniak, dr hab. inż. B. Czerniejewska-Surma, prof. nadzw., Zaklad Towaroznawstwa i Oceny Jakości, Wydz. Nauk o Żywności i Rybactwa, Zachodniopomorski Uniwersytet Technologiczny w Szczecinie, ul. Papieża Pawła VI 3, 71-459 Szczecin, dr inż. O. Surma, Katedra Dietetyki i Kosmetologii, Wydz. Kultury Fizycznej i Ochrony Zdrowia, Państwowa Wyższa Szkoła Zawodowa w Koninie, ul. Przyjaźni 1, 62-510 Konin, prof. dr hab. P. Zapletal, Zakład Hodowli Bydła, Wydz. Hodowli i Biologii Zwierząt, Uniwersytet Rolniczy w Krakowie, al. Mickiewicza 24/28, 30-059 Kraków. Kontakt:dominika.plust@zut.edu.pl 


\section{Wprowadzenie}

Miód znany jest ludziom od wieków nie tylko jako naturalna substancja słodząca, ale także lecznicza [16]. Właściwości prozdrowotne miodów wynikają z dużej zawartości polifenoli, a także innych związków aktywnych, w tym o charakterze przeciwutleniającym, które ograniczają rozwój chorób układu krążenia, cukrzycy czy chorób zwyrodnieniowych $[9,16,19]$. Zawartość przeciwutleniaczy w miodach jest uzależniona od wielu czynników, m.in. od pochodzenia botanicznego, warunków środowiskowych i klimatycznych czy sposobu ich pozyskiwania [2, 24]. Miód pszczeli spożywany jest jako dodatek do dań, ale jest także istotnym składnikiem miodu pitnego.

Dwójniaki to wyroby winiarskie należące do miodów pitnych - napojów alkoholowych powstających w wyniku fermentacji brzeczki miodowej. W literaturze anglojęzycznej zwane są także winem miodowym [13]. W przypadku dwójniaków stosunek objętościowy miodu do wody wynosi $1: 1(\mathrm{v} / \mathrm{v})$ [14]. Nazewnictwo miodów pitnych oraz wymogi jakościowe są ściśle sprecyzowane w polskich przepisach prawnych [20, 22].

Na jakość miodów pitnych mają wpływ zastosowane w procesie technologicznym dodatki w postaci soków owocowych, ziół czy przypraw korzennych (np. goździki, cynamon, gałka muszkatołowa). Na wzbogacenie profilu smakowo-zapachowego wpływa także pominięcie sycenia miodów pitnych (ogrzewania brzeczki miodowej do temp. $95-105^{\circ} \mathrm{C}$ ), dzięki czemu możliwe jest zachowanie lotnych związków aromatycznych $[15,12]$.

Zarówno miód, jak i fermentowane produkty alkoholowe uzyskane z niego uznawane są w piśmiennictwie za środki spożywcze o korzystnych właściwościach przeciwutleniających $[1,2,5,8,10,12]$, zaś dwójniaki cechują się korzystnym stosunkiem jakości do ceny. Zawierają one także więcej miodu w brzeczce niż trójniaki czy czwórniaki.

Celem pracy była ocena właściwości przeciwutleniających wybranych dwójniaków. W związku z tym, że nie jest to trunek spożywany jednorazowo w większych ilościach, podjęto decyzję o zbadaniu wpływu czasu przechowywania na te parametry.

\section{Material i metody badań}

Materiał do badań stanowiło 5 rodzajów miodów pitnych zakupionych w krajowych supermarketach: dwójniak sycony z miodu lipowego (1), dwójniak niesycony $z$ dodatkiem soku z malin (2), dwójniak gronowy sycony (3), dwójniak sycony z nektarowego miodu pszczelego z dodatkiem przypraw korzennych i soku z czarnej porzeczki (4), dwójniak niesycony z wyciągiem z kory dębu, ziół i przypraw (5).

Właściwości przeciwutleniające oznaczano w wodnych roztworach miodów pitnych bezpośrednio po otwarciu butelek oraz po 7 i 180 dniach przechowywania bute- 
lek ponownie zamkniętych i przechowywanych w warunkach chłodniczych (temp. $3 \pm$ $1{ }^{\circ} \mathrm{C}$ ). Każdą próbę do badań rozcieńczano pięciokrotnie przy użyciu wody destylowanej. Analizę właściwości przeciwutleniających przeprowadzano za pomocą metod spektroskopowych. Pojemność przeciwutleniającą mierzono metodą TEAC (Trolox Equivalent Antioxidant Capacity) [18]. W tym celu wygenerowano stabilne kationorodniki $\mathrm{ABTS}^{+}$, z których wykonano roztwór roboczy. $30 \mu$ rozcieńczonej próbki mieszano z $3 \mathrm{ml}$ odczynnika roboczego zawierającego znaną ilość kationorodników ABTS $^{+}$. Absorbancję mierzono po 30 min przy długości fali $\lambda=734 \mathrm{~nm}$. Zdolność redukującą oznaczano za pomocą metody FRAP (Ferric Reducing Antioxidant Power) [4]. Wykonano roztwór roboczy poprzez połączenie $300 \mathrm{mM} / 1$ buforu octanowego o pH 3,6, $20 \mathrm{mM} / 1 \mathrm{FeCl}_{3}$ i $10 \mathrm{mM} / 1 \mathrm{TPTZ}$ w $40 \mathrm{mM} / 1 \mathrm{HCl}$ w proporcji $10: 1: 1$ (v : v : v). $3 \mathrm{ml}$ roztworu roboczego mieszano ze $100 \mu 1$ badanych roztworów miodów pitnych i inkubowano przez 30 min. Pomiar absorbancji wykonywano przy długości fali $\lambda=$ $593 \mathrm{~nm}$. Oznaczano także zawartość polifenoli ogółem według Folina-Ciocalteu'a [26]. W tym celu $50 \mu 1$ próby dodawano do $1,5 \mathrm{ml}$ 7,5-procentowego roztworu $\mathrm{Na}_{2} \mathrm{CO}_{3}$ oraz 1,5 ml odczynnika F-C (rozcieńczonego w wodzie destylowanej w stosunku 1 : 10). Pomiar absorbancji wykonywano po $60 \min$ przy $\lambda=750 \mathrm{~nm}$. Wszystkie pomiary wykonano w trzech powtórzeniach. Do pomiaru absorbancji używano spektrofotometru He $\lambda$ ios $\varepsilon$ (firmy ThermoSpectronic, USA).

Wyniki opracowano ststystycznie przy użyciu programu Statistica 13.1. Przeprowadzono jednoczynnikową analizę wariancji, a istotność różnic między wartościami średnimi oszacowano przy użyciu testu Tukeya $(\mathrm{p} \leq 0,05)$.

\section{Wyniki i dyskusja}

Pojemność przeciwutleniająca miodów pitnych bezpośrednio po otwarciu opakowania była zróżnicowana i zawierała się w zakresie: $0,51 \div 2,36 \mathrm{mM} \mathrm{TE} / 1$, średnio 1,38 mM TE/1 (tab. 1). Wyniki własne pojemności przeciwutleniającej są niższe od uzyskanych przez Akalina i wsp. (3,89 $\div 4,13 \mathrm{mM}$ TE/l miodu pitnego) [1] oraz zbliżone do tych, które uzyskali Czabaj i wsp. (1,05 $\div 2,59 \mathrm{mM}$ TE/l) [5]. Przechowywanie produktów w ponownie zamkniętym opakowaniach w warunkach chłodniczych przez krótki czas $(7$ dni) nie wpłynęło istotnie na pojemność przeciwutleniającą, natomiast podczas długiego przechowywania (180 dni $)$ zaobserwowano statystycznie istotny wzrost tego parametru w przypadku dwóch miodów (1 i 5). Wyniósł on odpowiednio 0,52 i 0,24 mM TE/l. Może to wynikać $\mathrm{z}$ dalszych przemian związków reaktywnych powstałych w wyniku fermentacji czy dojrzewania, co stwierdzili García-Falcón i wsp. [8] w badaniach win gronowych, które, podobnie jak miody pitne, zawierają m.in. związki polifenolowe i są produktem fermentacji alkoholowej. W badaniach własnych zawartość związków polifenolowych była silnie skorelowana z pojemnością przeciwutleniającą $(\mathrm{r}=0,71)$. 
Tabela 1. Pojemność przeciwutleniająca wybranych miodów pitnych oznaczona metodą TEAC

Table 1. Antioxidant capacity of selected meads as measured by TEAC

\begin{tabular}{|c|c|c|c|}
\hline \multirow{2}{*}{$\begin{array}{c}\text { Symbol miodu } \\
\text { pitnego } \\
\text { Symbol of mead }\end{array}$} & \multicolumn{3}{|c|}{ TEAC [mM TE/l] } \\
\cline { 2 - 4 } & 0 & 7 & 180 \\
\hline 1 & $0,73^{\mathrm{aAB}} \pm 0,17$ & $1,05^{\mathrm{abB}} \pm 0,19$ & $1,25^{\mathrm{bB}} \pm 0,22$ \\
\hline 2 & $1,08^{\mathrm{aB}} \pm 0,13$ & $1,25^{\mathrm{abB}} \pm 0,18$ & $1,30^{\mathrm{abB}} \pm 0,21$ \\
\hline 3 & $0,51^{\mathrm{aA}} \pm 0,14$ & $0,68^{\mathrm{aA}} \pm 0,15$ & $0,64^{\mathrm{aA}} \pm 0,12$ \\
\hline 4 & $2,22^{\mathrm{aC}} \pm 0,21$ & $2,43^{\mathrm{aC}} \pm 0,22$ & $2,39^{\mathrm{aC}} \pm 0,23$ \\
\hline 5 & $2,36^{\mathrm{aC}} \pm 0,12$ & $2,50^{\mathrm{abC}} \pm 0,08$ & $2,60^{\mathrm{bC}} \pm 0,10$ \\
\hline
\end{tabular}

Objaśnienia / Explanatory notes:

W tabeli przedstawiono wartości średnie \pm odchylenia standardowe / Table shows mean values \pm standard deviations; $\mathrm{n}=3$; $\mathrm{a}, \mathrm{b}, \mathrm{c}$ - wartości średnie $\mathrm{w}$ wierszach oznaczone różnymi literami różnią się statystycznie istotnie $(\mathrm{p} \leq 0,05) /$ mean values denoted by different letters in rows differ statistically significantly $(\mathrm{p} \leq 0.05) ; \mathrm{A}, \mathrm{B}, \mathrm{C}$ - wartości średnie w kolumnach oznaczone różnymi literami różnią się statystycznie istotnie $(\mathrm{p} \leq 0,05) /$ mean values denoted by different letters in columns differ statistically significantly $(\mathrm{p} \leq 0.05)$.

Tabela 2. Zdolność redukująca wybranych miodów pitnych oznaczona metodą FRAP Table 2 Reducing abilities of selected meads as measured by FRAP

\begin{tabular}{|c|c|c|c|}
\hline \multirow{2}{*}{$\begin{array}{c}\text { Symbol miodu } \\
\text { pitnego } \\
\text { Symbol of mead }\end{array}$} & \multicolumn{3}{|c|}{ FRAP [mM TE/l] } \\
\cline { 2 - 4 } & 0 & 7 & 180 \\
\hline 1 & $1,28^{\mathrm{bA}} \pm 0,05$ & $1,16^{\mathrm{aA}} \pm 0,06$ & $0,89^{\mathrm{aA}} \pm 0,21$ \\
\hline 2 & $2,23^{\mathrm{CC}} \pm 0,07$ & $2,10^{\mathrm{bC}} \pm 0,05$ & $1,90^{\mathrm{aC}} \pm 0,12$ \\
\hline 3 & $1,68^{\mathrm{bB}} \pm 0,15$ & $1,46^{\mathrm{bB}} \pm 0,12$ & $1,13^{\mathrm{aB}} \pm 0,01$ \\
\hline 4 & $3,07^{\mathrm{bE}} \pm 0,11$ & $3,01^{\mathrm{bE}} \pm 0,12$ & $2,77^{\mathrm{aE}} \pm 0,11$ \\
\hline 5 & $2,76^{\mathrm{bD}} \pm 0,08$ & $2,58^{\mathrm{aD}} \pm 0,07$ & $2,48^{\mathrm{aD}} \pm 0,08$ \\
\hline
\end{tabular}

Objaśnienia jak pod tab. 1. / Explanatory notes as in Tab.1.

Właściwości redukujące miodów pitnych mieściły się w zakresie $1,28 \div 3,07 \mathrm{mM}$ TE/l, średnio - 2,20 mM TE/l (tab. 2). Miód 1 wyprodukowany z miodu lipowego charakteryzował się statystycznie istotnie niższymi wartościami zdolności redukującej niż pozostałe miody. Zdolność redukująca badanych miodów pitnych była ok. 2 razy wyższa od wartości uzyskanych przez Czabaja i wsp. [5], którzy zmierzyli wartości w zakresie $0,53 \div 1,37 \mathrm{mM}$ TE/l. Wymienieni autorzy użyli do swoich badań miodów pitnych wytworzonych na bazie miodów wielokwiatowych oraz spadziowych, a pominęli dodatki, takie jak soki owocowe czy przyprawy korzenne. Wilczyńska [23] dowiodła, że miody lipowe odznaczają się większą aktywnością przeciwutleniającą aniżeli miody wielokwiatowe, a więc $\mathrm{z}$ dużym prawdopodobieństwem $\mathrm{i}$ napoje alkoholowe wyprodukowane na ich bazie. Może to być także wyjaśnieniem różnic 
między właściwościami redukującymi pierwszego lipowego miodu pitnego bez dodatków (1,28 mM TE/l) a wartościami uzyskanymi przez Czabaja i wsp. [5].

Zaobserwowano także, że miody pitne z dodatkiem soku z owoców jagodowych (malin, czarnej porzeczki) charakteryzują się większą zdolnością redukującą. Prawdopodobnie jest to spowodowane dużą zawartością witaminy $\mathrm{C} \mathrm{w}$ badanych miodach pitnych. Człapka-Matysik i wsp. [6] wykazali, że sok z czarnej porzeczki bardzo dobrze przeciwdziała reakcjom wolnorodnikowym. Natomiast Baranowska i wsp. [3] donoszą, że maliny są dobrym źródłem zarówno polifenoli, jak i kwasu askorbinowego. Istotne obniżenie zdolności redukującej miodów pitnych 2 i 4 może wynikać zarówno ze strat wrażliwej na przechowywanie witaminy C [16], jak i polifenoli [21], na co wskazuje bardzo wysoki współczynnik korelacji pomiędzy zdolnością redukującą a zawartością polifenoli ogółem $(\mathrm{r}=0,84)$.

Zawartość polifenoli ogółem oznaczona metodą Folina-Ciocalteu'a wyniosła $122,6 \div 348,2 \mathrm{mg} \mathrm{kw}$. galusowego/1, średnio - 250,82 mg kw. galusowego/l (tab. 3). Najmniejszą zawartość polifenoli ogółem stwierdzono w miodzie pitnym bez deklarowanych dodatków (1).

Tabela 2. Zawartość polifenoli w wybranych miodach pitnych oznaczona metodą Folina-Ciocalteu'a Tabela 3. Contet of polyphenols in selected meads as measured by Folin-Ciocalteu

\begin{tabular}{|c|c|c|c||}
\hline \multirow{2}{*}{$\begin{array}{c}\text { Symbol miodu } \\
\text { pitnego }\end{array}$} & \multicolumn{3}{|c|}{$\begin{array}{c}\text { Zawartość polifenoli [mg kwasu galusowego/l] } \\
\text { Content of polyphenols [mg gallic acid/l] }\end{array}$} \\
\cline { 2 - 4 } & \multicolumn{3}{|c||}{ Dzień przechowywania / Storage day } \\
\cline { 2 - 4 } & 0 & 7 & 180 \\
\hline 1 & $122,6^{\mathrm{cA}} \pm 9,2$ & $111,4^{\mathrm{bA}} \pm 3,5$ & $226,7^{\mathrm{aC}} \pm 4,3$ \\
\hline 2 & $256,3^{\mathrm{cB}} \pm 12,0$ & $238,2^{\mathrm{bB}} \pm 5,8$ & $219,4^{\mathrm{aB}} \pm 3,8$ \\
\hline 3 & $234,0^{\mathrm{bB}} \pm 10,4$ & $234,0^{\mathrm{bB}} \pm 7,2$ & $265,7^{\mathrm{aD}} \pm 11,8$ \\
\hline 4 & $293,9^{\mathrm{bC}} \pm 11,9$ & $292,5^{\mathrm{bC}} \pm 13,2$ & $331,5^{\mathrm{aE}} \pm 7,8$ \\
\hline 5 & $348,2^{\mathrm{bD}} \pm 8,4$ & $353,7^{\mathrm{bD}} \pm 10,2$ & \\
\hline
\end{tabular}

Objaśnienia jak pod tab. 1. / Explanatory notes as in Tab.1.

W miodach pitnych, których skład producent uzupełnił sokiem owocowym czy przyprawami wykazującymi aktywność przeciwutleniającą, wartości te były statystycznie istotnie wyższe, czego przyczyną mogły być zastosowane dodatki. Michalak-Majewska i wsp. [17] dowiedli, że sok z czarnej porzeczki zawiera znacznie więcej polifenoli aniżeli inne analizowane soki $(497,1 \mathrm{mg} \mathrm{kw}$. galusowego/l), z czego znaczną ilość stanowią antocyjany należące do flawonoidów. Miód pitny 5 swoją wysoką aktywność przeciwutleniającą prawdopodobnie może zawdzięczać zarówno pominięciu procesu sycenia, jak i obecności deklarowanego przez producenta wyciągu $\mathrm{z}$ kory dębu. Zawiera ona bowiem należące do flawonoidów niehydrolizujące taniny 
(estry kwasu elaginowego lub galusowego i niearomatycznych polioli lub monosacharydów) [11]. Duda-Chodak i wsp. [7] dowiedli, że kora dębu jest bardzo cennym źródłem związków o charakterze przeciwutleniającym, łatwo ekstrahowanym w roztworach alkoholowych. Zaobserwowano zbieżność niniejszych badań z analizą dwójniaków przeprowadzoną przez Michalak-Majewską i wsp. [18]. Autorzy donoszą, że zawartość związków polifenolowych w próbach dwójniaków wynosiła 16,2 mg kwasu galusowego/100 $\mathrm{cm}^{3}$. Czabaj wsp. [5] wykazywali zawartość polifenoli ogółem na poziomie $177,30 \div 446,10 \mathrm{mg} \mathrm{kw}$. galusowego/l, czyli w zakresie bardzo zbliżonym do wyników uzyskanych w niniejszej pracy. Należy mieć na uwadze, że badane przez przytaczanych autorów miody pitne mogły charakteryzować się dodatkiem soku owocowego oraz/lub przypraw, jednak szczegółowe informacje nie zostały zamieszczone w cytowanych publikacjach. Zawartość polifenoli ogółem po 7 dniach przechowywania wskazuje na istotne zmniejszenie wartości tego parametru w miodach pitnych 4 i 5. Półroczny okres przechowywania spowodował istotną redukcję zawartości tego składnika we wszystkich miodach. Na podobną tendencję wskazywali wcześniej inni autorzy przeprowadzający analizę miodów pitnych i innych roślinnych napojów fermentowanych. $[8,10,12]$.

\section{Wnioski}

1. Miody pitne - dwójniaki są dobrym źródłem związków o charakterze przeciwutleniającym.

2. Krótkotrwałe przechowywanie chłodnicze nie wpłynęło istotnie na zmianę zawartości związków przeciwutleniających w badanych miodach pitnych.

3. Długotrwałe przechowywanie miodów pitnych wpłynęło na zmniejszenie zawartości polifenoli ogółem i tym samym na ich zdolność redukującą.

4. Miody pitne $\mathrm{z}$ dodatkiem soków owocowych (głównie z owoców jagodowych), przypraw korzennych czy wyciągu z kory dębu charakteryzowały się wyższą aktywnością przeciwutleniającą i było to skorelowane z zawartością polifenoli ogółem.

\section{Literatura}

[1] Akalın H., Bayram M., Anl R.E.: Determination of some individual phenolic compounds and antioxidant capacity of mead produced from different types of honey. J. Instit. Brewing, 2017, 1 (123), 167-174.

[2] Alvarez-Suarez J.M., Tulipani S., Romandini S., Bertoli E., Battino M.: Contribution of honey in nutrition and human health: A review. Mediterr. J. Nutr. Metab., 2010, 3 (1), 15-23.

[3] Baranowska A., Radwańska K., Zarzecka K., Gugała K., Mystkowska I.: Właściwości prozdrowotne owoców maliny właściwej (Rubus idaeus L.). Probl. Hig. Epidemiol., 2015, 96 (2), 406-409. 
[4] Benzie I.F.F., Strain J.J.: The ferric reducing ability of plasma (FRAP) as measure of antioxidant power: The FRAP assy. Ann. Biochem., 1996, 239 (1), 70-76.

[5] Czabaj S., Kawa-Rygielska J., Kucharska A.Z., Kliks J.: Effects of mead wort heat treatment on the mead fermentation process and antioxidant activity. Molecules, 2017, 22 (5), \#803.

[6] Człapka-Matysik M., Fejfer M., Gramza-Michałowska A., Kostrzewa-Tarnowska A., Jeszka J.: Właściwości antyrodnikowe wybranych soków owocowych dostępnych na polskim rynku. Probl. Hig. Epidemiol., 2011, 92 (4), 991-993.

[7] Duda-Chodak A., Tarko T., Rus M.: Antioxidant activity of selected herbal plants. Herba Polonica, 2009, 55 (4), 65-77.

[8] García-Falcón M.S., Pérez-Lamela C., Martínez-Carballo E., Simal-Gándara J.: Determination of phenolic compounds in wines: Influence of bottle storage of young red wines on their evolution. Food Chem., 2007, 105 (1), 248-259.

[9] Hossen S., Ali Y., Jahurul M.H.A., Abdel-Daim M.M., Gan S.H., Khalil I.: Beneficial roles of honey polyphenols against some human degenerative diseases: A review. Pharmacological Reports, 2017, 69 (6), 1194-1205.

[10] Ivanova V., Vojnoski B., Stefova M.: Effect of winemaking treatment and wine aging on phenolic content in Vranec wines. J. Food Sci. Technol., 2012, 49 (2), 161-172.

[11] Jeszka M., Flaczyk E., Kobus-Cisowska J., Dziedzic K.: Związki fenolowe - Charakterystyka i znaczenie w technologii żywności. Nauka, Przyroda, Technologie, 2010, 4 (2), 1-13.

[12] Kahoun D., Řezková S., Královský.: Effect of heat treatment and storage conditions on mead composition, Food Chem., 2017, 219, 357-363.

[13] Koguchi M., Saigusa N., Teramoto Y.: Production and antioxidative activity of mead from honey and black rice (Oryza sativa var. Indica cv. Shiun). J. Instit. Brewing, 2009, 115 (3), 238-242.

[14] Kolanowski W.: Szlachecki trunek. Miody pitne - rodzaje i etapy wyrobu. Przegl. Gastr., 2011, 65 (9), 32-33.

[15] Luty J.: Miody pitne sycone, a może lepiej niesycone? Przem. Ferm. Owoc. Warz., 2009, 7-8, 50-51.

[16] Meo S.A., Al-Asiri S.A., Mahesar A.L., Ansari M.J.: Role of honey in modern medicine. Saudi J. Biolog. Sci., 2017, 24 (5), 975-978.

[17] Michalak-Majewska M., Żukiewicz-Sobczak W., Kalbarczyk J.: Ocena składu i właściwości soków owocowych preferowanych przez konsumentów. Bromat. Chem. Toksykol., 2009, 42 (3), 836-841.

[18] Puzanowska-Tarsiewicz H., Kuźmicka L., Tarasiewicz M.: Antyoksydanty a reaktywne formy tlenu. Bromat. Chem. Toksykol., 2010, 43 (1), 9-14.

[19] Re R., Pellegrini N., Proteggente A., Pannala A., Yang M., Rice-Evans C.: Antioxidant activity applying an improved ABTS radical cation decolorization assy. Free Radic. Biol. Med., 1999, 26 (910), 1231-1237.

[20] Rozporządzenie Ministra Rolnictwa i Rozwoju Wsi z dnia 22 maja 2013 r. w sprawie rodzajów fermentowanych napojów winiarskich oraz szczegółowych wymagań organoleptycznych, fizycznych i chemicznych, jakie powinny spełniać te napoje. Dz. U. 2013, poz. 633.

[21] Socha R., Pająk P., Fortuna T., Buksa K.: Phenolic profile and antioxidant activity of Polish meads, Int. J. Food Proper., 2015, 18, 2713-2725.

[22] Ustawa z dnia 12 maja 2011 r. o wyrobie i rozlewie wyrobów winiarskich, obrocie tymi wyrobami i organizacji rynku wina. Dz. U. 2011 r. Nr 120, poz. 690.

[23] Wilczyńska A.: Zmiany barwy oraz aktywności antyoksydacyjnej miodów pszczelich podczas przechowywania. Bromat. Chem. Toksykol., 2011, 44 (3), 945-950.

[24] Wollgast J.: The contest and effects of polyphenols in chocolate. Qualitative and quantitative analyses of polyphenols in chocolate and chocolat raw products as well as evaluation of potential implications of chocolate consumption in human health. Praca doktorska wykonana na Uniwersytecie w Giessen, Niemcy, 2004. 


\title{
ASSESSING ANTIOXIDANT ACTIVITY OF SELECTED MEADS 1: 1 AND CHANGES THEREIN DURING STORAGE
}

\begin{abstract}
S u m m a r y
Meads are alcoholic products made by fermenting honey wort. Raw materials used to produce meads (honey, spices, fruit juices) are a rich source of compounds characterised by good antioxidant properties. Those compounds were determined in the aquous solutions of mead; the analyses were performed immediately after opening the bottles and after 7 and 180 days of storage. The analyses proved that the good and varied antioxidant properties featured the (1:1) meads. The (1:1) meads with fruit juices added and those subjected and/or not subjected to a satiation process were characterised by a higher antioxidant activity (TEAC) at a level of $1.08 \div 2.36 \mathrm{mM} \mathrm{TE} / 1$ compared to the saturated meads and/or without additives at a level of $0.51 \div 0.73 \mathrm{mM}$ TE/l. The reducing properties (FRAP) were within the range between 1.28 and $3.07 \mathrm{mM} \mathrm{TE} / 1$. A significant decrease in this parameter was found during storage. The analyses also confirmed that adding other ingredients by the producer might cause the content of total polyphenols to increase almost three times (the linden mead without additives: $122.6 \mathrm{mg}$ of gallic acid/l; the honey with the extract from the oak bark, herbs, and spices added: $348.2 \mathrm{mg}$ of galic acid/1). Furthermore, it was reported that, in most cases, both the short- and long-term storage of meads did not significantly affect their antioxidant capabilities; however, it significant impacted the reducing capabilities and the content of total polyphenol.
\end{abstract}

Key words: $(1: 1)$ mead, antioxidant properties, TEAC, FRAP, total polyphenols, cold storage 